\title{
MULTICRITERIA DECISION MAKING MODEL FOR THE NEW TEAM MEMBER SELECTION BASED ON INDIVIDUAL AND GROUP-RELATED FACTORS
}

\author{
Jakub WOJNAR \\ Faculty of Management \\ Warsaw University of Technology, Warsaw, Poland \\ email: jakub.wojnar@gmail.com
}

\begin{abstract}
This paper presents a novel approach to the team building emphasizing group-related attributes of potential candidates instead of focusing on their individual characteristics during the recruitment process. The main assumption is that the teamwork capabilities are equally if not more important than individual skills or competences when selecting new team member. Myers-Briggs Type Indicator is used for analyzing teamwork capabilities and multicriteria decision making model will be developed as a final solution.
\end{abstract}

Key words: team, teamwork, personality types, MBTI, cognitive proximity, recruitment process.

1

\section{Introduction}

There is no doubt that nowadays teamwork is a key factor of the successful company. Teamwork can be defined as a collaboration of two or more people on a common task [13] and it improves innovativeness of the company [20]. According to Hayes teamwork encourages people to be more professional and responsible [12]. It also helps to empower employees and gives the opportunity of making decision to the people who perform the tasks [17]. Very often teams are used for in order to manage change, reduce costs, increase effectiveness and productivity [2]. Unfortunately gathering a group of people and just calling them a team is not a solution. It is important to note that there is a significant difference between group and team and is related to the way that group and team achieve their goals as well as to the evaluation of their performance. Members of the group are responsible and accountable for individual work products and in the same way is measured their performance whereas team's performance is measured as a function of individual and collective efforts and results as all members share individual and mutual accountability [16]. The main differences between the group and the team are described in Table 1. and it is a base for defining the main problem described in Section II.

There are two important differences in the table above that have solid consequences for the work results. Team members' mutual accountability and collective work products lead to the fact that team's performance is directly impacted by cooperation capabilities and relationships between team members. This does not exist in a group as group's members are treated individually.

Table 1. Group vs. Team

(source: [16])

\begin{tabular}{|l|l|}
\hline \multicolumn{1}{|c|}{ GROUP } & \multicolumn{1}{c|}{ TEAM } \\
\hline Strong, clearly focused leader & Shared leadership roles \\
\hline Individual accountability & Individual and mutual accountability \\
\hline $\begin{array}{l}\text { The group's purpose is the same as the } \\
\text { broader organizational mission }\end{array}$ & $\begin{array}{l}\text { Specific team purpose that the team itself } \\
\text { delivers }\end{array}$ \\
\hline Individual work products & Collective work products \\
\hline Runs efficient meetings & $\begin{array}{l}\text { Encourages open-ended discussion and active } \\
\text { problem-solving meetings }\end{array}$ \\
\hline $\begin{array}{l}\text { Measures its effectiveness indirectly by its } \\
\text { influence on others (such as financial } \\
\text { performance of the business) }\end{array}$ & $\begin{array}{l}\text { Measures performance directly by assessing } \\
\text { collective work products }\end{array}$ \\
\hline Discusses, decides, and delegates & $\begin{array}{l}\text { Discusses, decides, and does real work } \\
\text { together }\end{array}$ \\
\hline
\end{tabular}


But in case of a team if team members are not able to cooperate and their professional relations are below the sufficient level such team will not be successful even though all individuals are very competent [8]. Sometimes very competent experts are selected based solely on their professional skills which do not include social and communication attributes and that may not have suitable personalities for team work [17]. Team composition is an important issue for a team success and includes such factors as composition of member's personality, team leadership or communication and coordination within a team [10]. It was noted already in the beginning of $19^{\text {th }}$ century by the Polish economist, engineer and management science researcher Karol Adamiecki that besides two types of harmony that are crucial for effectiveness of collective work harmony of choice and harmony of doing - there is also a third one, the harmony of spirit which deals only with human factors and should connect all people working together [1].

This paper focuses on a team as defined by Katzenbach and Smith [16]: "A team is a small number of people with complementary skills who are committed to a common purpose, set of performance goals, and approach for which they hold themselves accountable" and elaborates on a team building method using individual (technical) and group (human) related factors with a main assumption taken from a software project teams that when talking about better team performance human attributes of team members are more important than their technological skills [10]. There are different types of teams: sales team, project teams, sport teams, R\&D teams, service teams, management teams, etc. In this paper IT Service Team is discussed. The role of such team within IT organization is to deliver and maintain IT services according to the Standard Level Agreement between the service provider (IT Service Team) and the customer (i.e. Global F\&C Team). Despite service delivery tasks discussed team also transforms into project team where all resources are used in the project mode, meaning the team provides unique end result in a limited time with limited cost. In the next sections when the problem is stated or the solution proposed described above IT Service Delivery team is meant.

This paper is organized as follows. In Section II a practical problem of recruiting a new member to the already existing and well performing team is described. Different aspects of selecting the optimal candidate from group-related and individual perspective are listed. Then a novel approach to the team building process with a focus on social and team working capabilities of potential candidates is proposed in Section III. The model as such is not created yet but its components are described. Section IV provides and illustrative example of the problem and its solution. Last two sections provide information on possible further research and conclude the paper with a short summary.

\section{The problem}

Having well organized team with competent members is a goal that many managers want to achieve. Such team when well managed will perform excellent using the synergy effect coming from complementary characteristics of its members. However in today's dynamic and turbulent environment in the most of the companies the only thing that is constant is a change. Enterprises change their strategies, goals and of course organizational structures. These changes lead many high performing teams to lose their members and the question arises of who should be hired in order to keep the team's performance on a sufficient level. Building a successful team of experts who will creatively and willingly cooperate with each other is a big challenge. Admittedly, a company success depends on its employees, their experiences, codified and tacit knowledge, competences and - above all - mutual cooperation, sharing information, trust, sympathy, understanding, etc. When observing sport teams (i.e. football) it can be easily seen that many times team consisting of players with "average" skills but cooperating and "feeling" each other on the field can outperform the team of "stars". The same applies to the business teams. When building a high performing team the cooperation ability of team members is more important than their individual attributes. But analyzing Human Resources Management literature it can be found that the most popular recruitment techniques and tools are based only on individual characteristics of candidates. Some of the most popular selection's techniques are references, interview, professional tests, intelligence tests, Assessment Center [15], applications analysis, bio-data analysis, 360-evaluation, executive search [18], education, academic results [3]. 


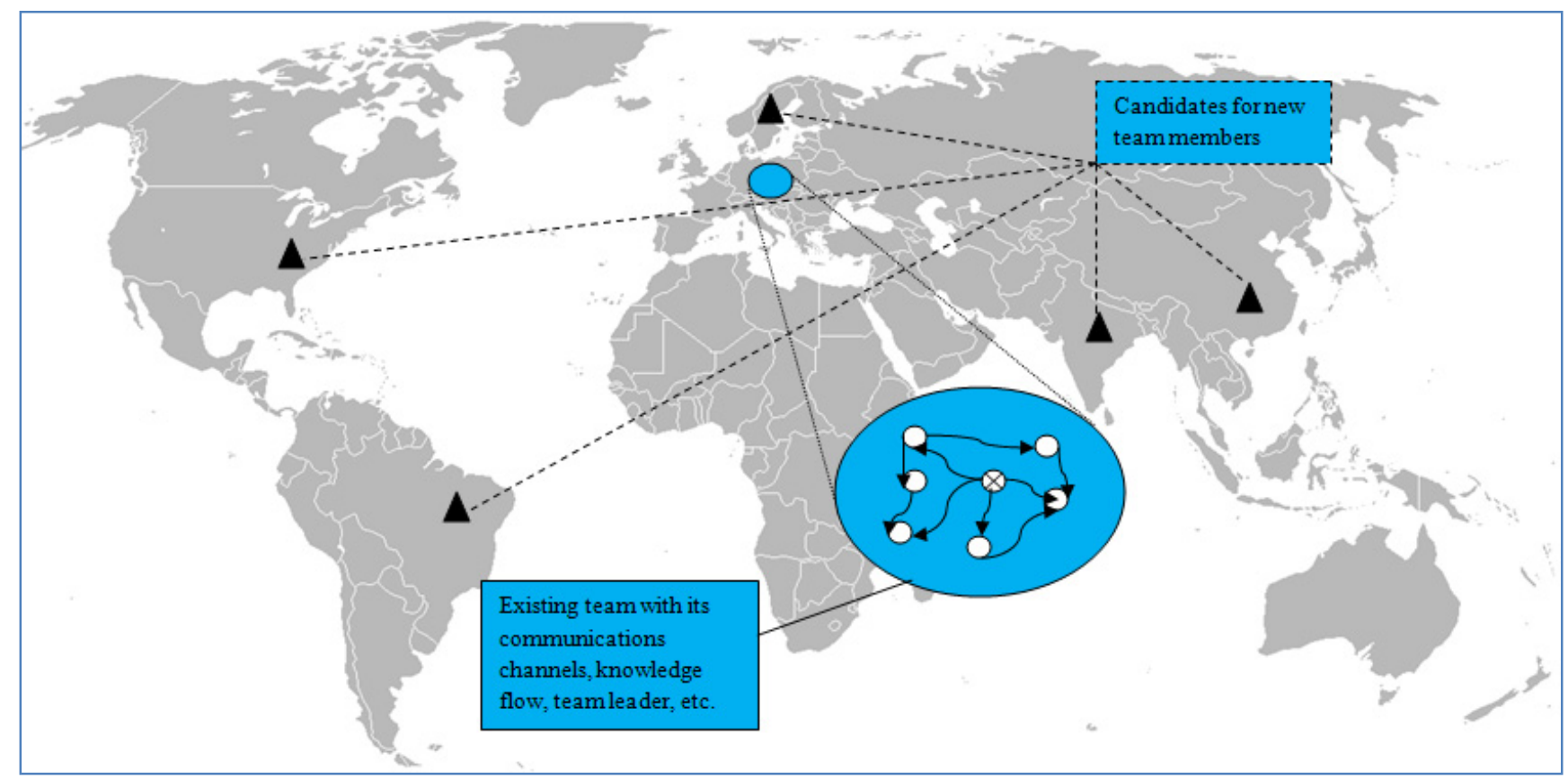

Figure 1. Recruitment Problem (source: self study)

This is confirmed by a small survey performed on 31 international companies - mainly from IT and ICT sector but not limited to - that were asked whether during the recruitment process they check the candidate's fitness into the team he or she will work in. Only five companies answered positively, meaning that prior to the recruitment process they evaluate and analyze existing team and based on that try to find a proper new team member. The rest of the companies recruit new employees using one or many from the methods listed above. Such techniques can answer a question whether a candidate is a leader type of person or prefers to be led however regardless of their sophistication; they are mostly focused only on the candidate's individual attributes without any reference to the team. Some authors mention about techniques that evaluate candidate's fitness into overall company's strategy or even the capability of creating human relations [3] however there is no mention about fitness into particular team. One of the main factors influencing team effectiveness is communication. It plays significant role in every type of teams and becomes crucial with a growing number of team members. The problem is how to choose the candidate for the existing team in order to maximize its performance based on candidate's skills and competences, teamwork capabilities and fitness to the team and last but not least geographical location. Fig. 1. illustrates the recruitment problem.
There is a IT Service Team (small circles) that possesses well established communication and knowledgeflow channels (arrows between the circles) and has its solid structure with formal leader (crossed circle), subject matters experts, support personnel. This team due to the organizational changes is forced to increase the number of its members by selecting one from the pool of candidates (triangles) that are dispersed geographically and poses different levels of competence, skills, experience and interpersonal capabilities.

In the next chapter a solution based on multicriteria decision model for the recruitment problem is proposed.

\section{Proposed solution}

The proposed solution is based on the assumption that team-working skills and cooperation capabilities of candidate are equally if not more important factors than his individual characteristics. It is based on a multicriteria decision model using two sets of criteria: individual and group related with emphasis on MyersBriggs Type Indicator and Cognitive Proximity. In order to make a team more effective such diversities as cognitive style, team role preferences or values must be smartly organized and managed [14]. One of the factors for a successful team is communication. 


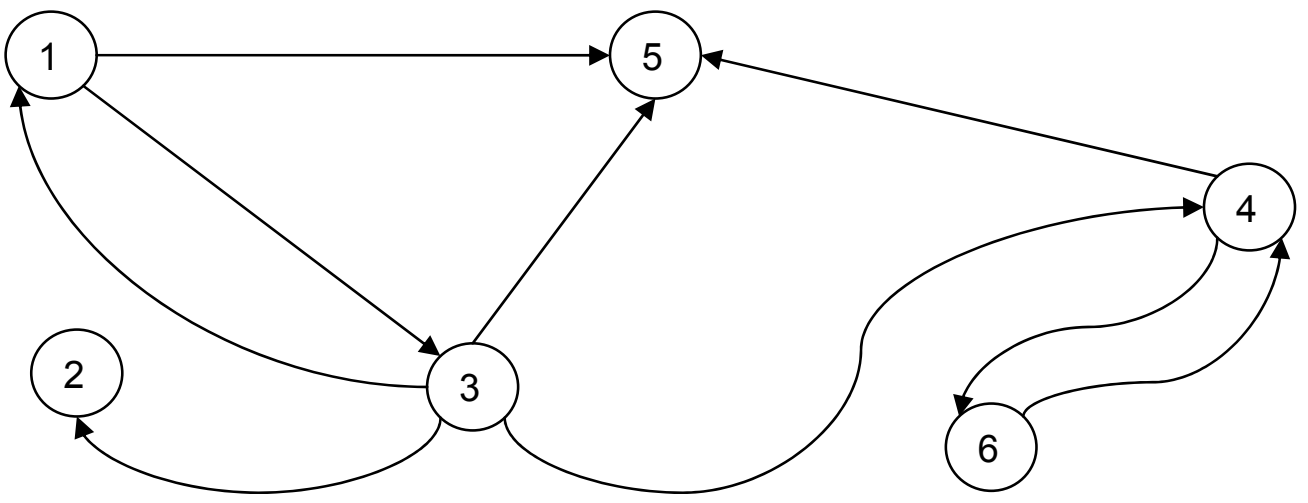

Figure 2. Knowledge flow between team members (source: self study)

In Opt and Loffredo's work can be found that introverts tend to be socially disadvantaged because of their communication preference and they see themselves as poor communicators [19]. That may have negative impact on the team's communication. However knowing the communication's preference of team members can increase tolerance and acceptance of those who are not feeling well with expressing externally [19] and thus improve the overall quality of team communication. In James Stapelton's research it can be found that there is a significant difference in the decision performance of teams if MBTI functions of team members taken into consideration [22]. Cognitively heterogeneous pairs of members in Sensing-Intuition MBTI function are outperforming only sensing pairs in decision performing but not homogenous intuitive pairs of members [9].

In a first stage the existing team is analyzed in order to determine communication channels and knowledge flows. This can be done by performing simple survey asking team members i.e. 'whom do they communicate with most often' or 'whom do they ask for an advice'. Results of the survey are represented by a digraph or by its matrix. An illustration of the example answer for the question of 'whom do you ask for an advice when performing daily work tasks' is presented on Fig. 2. Such question identifies the subject matter experts and the knowledge transfer within the team.

In above graph vertices represent team members and arcs the knowledge flow between the members. Subject matter experts and their level of importance in the knowledge transfer within a team is defined by the node's outdegree value (deg-(v)) ordered from highest to lowest. In our example:

$$
\begin{aligned}
& \operatorname{deg}^{-}(3)=4 \\
& \operatorname{deg}^{-}(1)=2 \\
& \operatorname{deg}^{-}(4)=2 \\
& \operatorname{deg}^{-}(6)=1 \\
& \operatorname{deg}^{-}(2)=0 \\
& \operatorname{deg}^{-}(5)=0
\end{aligned}
$$

That means that member (3) serves as a knowledge source for most of the team members and should be considered as main contact point for a new member in a process of induction into new tasks and responsibilities. The following team members with lower outdegree values should be treated accordingly.

Second stage of the team analysis will be based on the Myers-Briggs Type Indicator concept. It is based on Carl Jung's theory of psychological type. It assumes that every person has natural preference in perceiving the world and making decisions in the same way like with preference of using right hand over the left or vice versa [6]. This preference is defined by four pairs of dichotomous attributes: Extroversion/Introversion, Sensing/iNtuition, Thinking/Feeling and Perceiving/Judging [5]. Combination of one attribute from each pair creates sixteen psychological types that a person can be described by and they are listed in Table 2 .

Table 2. Psychological types (source: [5])

\begin{tabular}{|l|l|l|l|}
\hline ISTJ & ISFJ & INFJ & INTJ \\
\hline ISTP & ISFP & INFP & INTP \\
\hline ESTP & ESFP & ENFP & ENTP \\
\hline ESTJ & ESFJ & ENFJ & ENTJ \\
\hline
\end{tabular}


Table 3. Attribute relations

(source: [24])

\begin{tabular}{|c|c|c|c|c|c|}
\hline & $E$ & I & & $\mathrm{s}$ & $\mathrm{N}$ \\
\hline$E$ & + & $\mathrm{n}$ & $S$ & $\mathrm{n}$ & + \\
\hline \multirow[t]{2}{*}{1} & $\mathrm{n}$ & - & $\mathrm{N}$ & + & $\mathrm{n}$ \\
\hline & $\mathbf{T}$ & $\mathbf{F}$ & & $\mathrm{J}$ & $\mathbf{P}$ \\
\hline $\mathbf{T}$ & $\mathrm{n}$ & + & $\mathbf{J}$ & + & - \\
\hline$F$ & + & $\mathrm{n}$ & $\mathbf{P}$ & - & + \\
\hline
\end{tabular}

Each type shows such preference. For example a person characterized by type ISTJ is rather introvert that collects data by sensing makes decision by logical analysis and prefers systematic and planned way of acting. Then each of the MBTI types is decomposed in single attributes and those attributes are valued from the perspective of cooperation capabilities [24]. The pair of introvert vs. extrovert is quite easy to define as extroverts are outer world oriented and teamwork stimulates them. Such relation will be positive for cooperation. On the other hand it will be very difficult for two introverts to cooperate as they draw their energy from the focus on concepts and ideas and they need quiet time alone. And thus such relation will be negative. Relation between introvert and extrovert will be neutral from the teamwork perspective. People characterized by iNtuition attribute are able to create a vision from the scratch and set a future goal whereas Sensing team members will put this vision into realistic frame and make it happen [5]. Such relation is complementary and positive. Relations S-S and N-N are neutral as such people see the world in the same way and often such relation does not bring any creative impulse. The same rule applies to Thinking-Feeling relation. In case of Judging and Perceiving pairs the situation is different. J-J and P-P people share the same vision of the world and agree on the same values and norms. This is why such relations will be positive. On the other and J-P people will not be able to understand each other and foresee what the other is going to do $[7,8]$. This relation will be negative from the cooperation perspective. Above relations are summarized in Table 3. by assigning " + " for positive relation, " $n$ " for neutral and "-" for negative relation. Relations between single attributes of different dichotomies, i.e. Extrovert vs. Intuitive are not valued as they operate on different domains and are incomparable.

In Table 4. Saaty's fundamental scale for pairwise comparison is presented. It is used in order to quantify described attributes' relations. Explanation of the intensity of importance from the scale ideally fits to the purpose of valuing different types of relations between MBTI attributes.

Table 4. Fundamental scale (source: [21])

\begin{tabular}{|c|c|c|}
\hline $\begin{array}{ll}\text { Intensity } & \text { of } \\
\text { importance } & \end{array}$ & Definition & Explanation \\
\hline 1 & Equal importance & Two elements contribute equally to the objective \\
\hline 3 & Moderate importance & $\begin{array}{l}\text { Experience and judgement slightly favor one element } \\
\text { over another }\end{array}$ \\
\hline 5 & Strong importance & $\begin{array}{l}\text { Experience and judgement strongly favor one element } \\
\text { over another }\end{array}$ \\
\hline 7 & Very strong importance & $\begin{array}{l}\text { One element is favored very strongly over another, its } \\
\text { dominance is demonstrated in practice }\end{array}$ \\
\hline 9 & Extreme importance & $\begin{array}{l}\text { The evidence favoring one element over another is of } \\
\text { the highest possible order of affirmation }\end{array}$ \\
\hline $2,4,6,8$ & Intermediate importance & Used in case of need of compromise \\
\hline Reciprocals & \multicolumn{2}{|c|}{$\begin{array}{l}\text { If activity } i \text { has one of the above values in comparison to activity } j \text {, then activity } j \text { has } \\
\text { reciprocal value when compared with } i\end{array}$} \\
\hline
\end{tabular}


Table 5. Values of attribute relations (source: [24])

\begin{tabular}{|l|ll|l|ll|}
\hline & E & I & & S & N \\
\hline E & 5 & 1 & S & 1 & 5 \\
I & 1 & 0 & N & 5 & 1 \\
\hline & T & F & & J & P \\
\hline T & 1 & 5 & J & 5 & 0 \\
F & 5 & 1 & P & 0 & 5 \\
\hline
\end{tabular}

Table 6. MBTI types relations matrix

(source: [24])

\begin{tabular}{|c|c|c|c|c|c|c|c|c|c|c|c|c|c|c|c|c|}
\hline & ESTJ & ISTJ & ESFJ & ISFJ & ESTP & ISTP & ESFP & ISFP & ENTJ & INTJ & ENTP & INTP & ENFJ & INFJ & ENFP & INFP \\
\hline ESTJ & 12 & & & & & & & & & & & & & & & \\
\hline ISTJ & 8 & 7 & & & & & & & & & & & & & & \\
\hline ESFJ & 16 & 12 & 12 & & & & & & & & & & & & & \\
\hline ISFJ & 12 & 11 & 8 & 7 & & & & & & & & & & & & \\
\hline ESTP & 7 & 3 & 11 & 7 & 12 & & & & & & & & & & & \\
\hline ISTP & 3 & 2 & 7 & 6 & 8 & 7 & & & & & & & & & & \\
\hline ESFP & 11 & 7 & 7 & 3 & 16 & 12 & 12 & & & & & & & & & \\
\hline ISFP & 7 & 6 & 3 & 2 & 12 & 11 & 8 & 7 & & & & & & & & \\
\hline ENTJJ & 16 & 12 & 20 & 16 & 11 & 7 & 15 & 11 & 12 & & & & & & & \\
\hline INTJ & 12 & 11 & 16 & 15 & 7 & 6 & 11 & 10 & 8 & 7 & & & & & & \\
\hline ENTP & 11 & 7 & 15 & 11 & 16 & 12 & 20 & 16 & 7 & 3 & 12 & & & & & \\
\hline INTP & 7 & 6 & 11 & 10 & 12 & 11 & 16 & 15 & 3 & 2 & 8 & 7 & & & & \\
\hline ENFJ & 20 & 16 & 16 & 12 & 15 & 11 & 11 & 7 & 16 & 12 & 11 & 7 & 12 & & & \\
\hline INFJ & 16 & 15 & 12 & 11 & 11 & 10 & 7 & 6 & 16 & 11 & 7 & 6 & $B$ & 7 & & \\
\hline ENFP & 15 & 11 & 11 & 7 & 20 & 16 & 16 & 12 & 11 & 7 & 16 & 12 & 7 & 3 & 12 & \\
\hline INFP & 11 & 10 & 7 & 6 & 16 & 15 & 12 & 11 & 7 & 6 & 12 & 11 & 3 & 2 & 12 & 7 \\
\hline
\end{tabular}

Table 7. Normalized matrix

(source: [24])

\begin{tabular}{|c|c|c|c|c|c|c|c|c|c|c|c|c|c|c|c|c|}
\hline & ESTJ & ISTJ & ESFJ & ISFJ & ESTP & ISTP & ESFP & ISFP & ENTJ & INTJ & ENTP & INTP & ENFJ & INFJ & ENFP & INFP \\
\hline ESTJ & 0,60 & & & & & & & & & & & & & & & \\
\hline ISTJ & 0,40 & 0,35 & & & & & & & & & & & & & & \\
\hline ESFJ & 0,80 & 0,60 & 0,60 & & & & & & & & & & & & & \\
\hline ISFJ & 0,60 & 0,55 & 0,40 & 0,35 & & & & & & & & & & & & \\
\hline ESTP & 0,35 & 0,15 & 0,55 & 0,35 & 0,60 & & & & & & & & & & & \\
\hline ISTP & 0,15 & 0,10 & 0,35 & 0,30 & 0,40 & 0,35 & & & & & & & & & & \\
\hline ESFP & 0,55 & 0,35 & 0,35 & 0,15 & 0,80 & 0,60 & 0,60 & & & & & & & & & \\
\hline ISFP & 0,35 & 0,30 & 0,15 & 0,10 & 0,60 & 0,55 & 0,40 & 0,35 & & & & & & & & \\
\hline ENTJ & 0,80 & 0,60 & 1,00 & 0,80 & 0,55 & 0,35 & 0,75 & 0,55 & 0,60 & & & & & & & \\
\hline INTJ & 0,60 & 0,55 & 0,80 & 0,75 & 0,35 & 0,30 & 0,55 & 0,50 & 0,40 & 0,35 & & & & & & \\
\hline ENTP & 0,55 & 0,35 & 0,75 & 0,55 & 0,80 & 0,60 & 1,00 & 0,80 & 0,35 & 0,15 & 0,60 & & & & & \\
\hline INTP & 0,35 & 0,30 & 0,55 & 0,50 & 0,60 & 0,55 & 0,80 & 0,75 & 0,15 & 0,10 & 0,40 & 0,35 & & & & \\
\hline ENFJ & 1,00 & 0,80 & 0,80 & 0,60 & 0,75 & 0,55 & 0,55 & 0,35 & 0,80 & 0,60 & 0,55 & 0,35 & 0,60 & & & \\
\hline INFJ & 0,80 & 0,75 & 0,60 & 0,55 & 0,55 & 0,50 & 0,35 & 0,30 & 0,80 & 0,55 & 0,35 & 0,30 & 0,40 & 0,35 & & \\
\hline ENFP & 0,75 & 0,55 & 0,55 & 0,35 & 1,00 & 0,80 & 0,80 & 0,60 & 0,55 & 0,35 & 0,80 & 0,60 & 0,35 & 0,15 & 0,60 & \\
\hline INFP & 0,55 & 0,50 & 0,35 & 0,30 & 0,80 & 0,75 & 0,60 & 0,55 & 0,35 & 0,30 & 0,60 & 0,55 & 0,15 & 0,10 & 0,60 & 0,35 \\
\hline
\end{tabular}


Based on the above scale following values were applied to the MBTI relations:

- for negative relation - value 0 - in order to avoid negative numbers,

- for neutral relation - value 1 ,

- for positive relation - value 5 .

It must be stated here that the above values are chosen in a subjective way in order to emphasize the difference between the relations and to simplify further calculations.

Quantified attributes' relations are presented in Table 5. Individual attributes' relations are extrapolated to the whole types and MBTI types' relations matrix is created. This matrix is presented in Table 6. In order to simplify further calculations above matrix is normalized by dividing it by maximum value. Normalized matrix is presented in Table 7.

Above matrix can be read in following way: the best combination of types for cooperation is a pair with the highest value in the matrix. In our case the highest value equals 1 for pairs (ENFJ, ESTJ), (ENTJ, ESFJ), etc. On the other hand the worst combination of types for cooperation are pairs with lowest value in the matrix. In our example these are (INFP, INFJ), (INTP, INTJ), etc with value 0,1 . This table is used as follows. All members of existing team are MBTI analyzed and each member has one out of sixteen MBTI types assigned. The same applies to all candidates. Now candidates will be compared pairwise with previously subject matter experts of the team in order to find the highest values for such comparison. This will be the first group-related criterion for the final model.

Second group-related criterion is a competence level of candidate in relation to other team members. For that purpose Walukiewicz's concept of Cognitive Proximity will be used. Cognitive proximity called also technological proximity defines the cognitive distance between actors working on a particular problem [23]. It consists of codified and tacit knowledge related to the problem being solved as well as problem-related experience, differences and similarities of the actors. Cognitive proximity facilitates their creative cooperation and stimulates innovative processes involved in the act. It makes their communication easier and simplifies the learning process as well. In order to quantify our research and analysis, we introduce the utility measure $u$ of cognitive proximity (similar measure is used for oth- er proximities as well) that is expressed by a binary function below

$$
u(C P, E, H, t)=\left\{\begin{array}{l}
1 \text { if expert } E \text { is cognitively able } \\
\text { to co-operate with expert } H \\
\text { during time } t \\
0 \text { otherwise }
\end{array}\right.
$$

where $\mathrm{u}$ means utility function, $\mathrm{CP}$ - cognitive proximity, $\mathrm{E}$ and $\mathrm{H}$ are actors working on a specific Virtual Production Line and $t$ is a time period during which $\mathrm{E}$ and $\mathrm{H}$ cooperate. This function should be understood as follows: if two experts $\mathrm{E}$ and $\mathrm{H}$ are cognitively able to cooperate, that is to say, their codified and tacit knowledge levels allow them to cooperate on a specified problem during time $t$, our utility function yields the result of 1. Cognitive proximity is direct in a sense that we are interested both in actors and direct cognitive relations between them and that they have influence on that proximity. One could think that two actors working together should be as cognitively close to each other as possible, however too much cognitive proximity may be detrimental to learning and innovation [4].

Therefore another measure $d$ for expressing cognitive distance between actors that could be understood as difference in knowledge - tacit and codified, relevant to the problem - is introduced. The utility function curve in relation the distance has a shape similar to the bell curve, as shown in the Fig. 3. To achieve optimal productivity of two actors working on a problem, their cognitive proximity should look as shown. As cognitive proximity is very dependent on the problem being solved, the shape of the curves will vary accordingly, nevertheless the idea is that optimal utility will always be achieved at a similar point. Cognitive proximity is asymmetric which means that the knowledge absorption capacity of actor $\mathrm{E}$ is not the same as that of actor $H$, i.e. actor $\mathrm{E}$ may understand or even anticipate the ideas of actor $\mathrm{H}$ faster than actor $\mathrm{H}$ ideas of actor $\mathrm{E}$ [11].

Properties of utility and distance of proximity:

$$
\begin{aligned}
& \mathrm{d}(\mathrm{CP}, \mathrm{E}, \mathrm{H}, \mathrm{t}) \in[0,1] \\
& \mathrm{d}(\mathrm{CP}, \mathrm{E}, \mathrm{H}, \mathrm{t})=1 \Rightarrow \mathrm{u}(\mathrm{CP}, \mathrm{E}, \mathrm{H}, \mathrm{t})=0 \\
& \mathrm{~d}(\mathrm{CP}, \mathrm{E}, \mathrm{H}, \mathrm{t})=0 \Rightarrow \mathrm{E}=\mathrm{H} \Rightarrow \mathrm{u}(\mathrm{CP}, \mathrm{E}, \mathrm{H}, \mathrm{t})= \\
& \mathrm{u}(\mathrm{CP}, \mathrm{H}, \mathrm{E}, \mathrm{t})=0 \\
& \mathrm{u}(\mathrm{CP}, \mathrm{E}, \mathrm{H}, \mathrm{t}) \neq \mathrm{u}(\mathrm{CP}, \mathrm{H}, \mathrm{E}, \mathrm{t})
\end{aligned}
$$




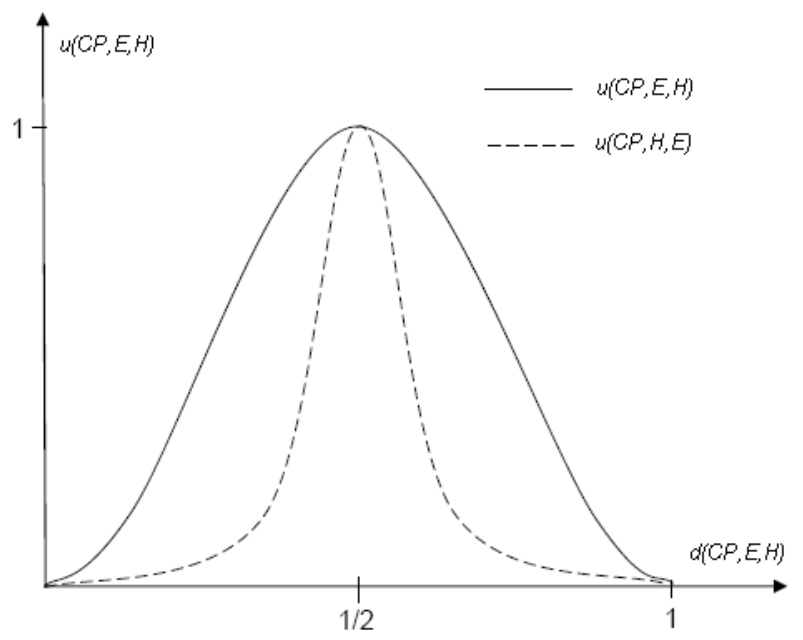

Figure 3. Utility measure of cognitive proximity in a given time $t$

(source: [23])

And they mean that distance between actors $\mathrm{E}$ and $\mathrm{H}$ is expressed as a value between 0 and 1 . If distance $\mathrm{d}$ equals 1 , then our previously defined utility measure equals 0 , meaning that those actors are not able to cognitively cooperate. If distance equals 0 , then actors $\mathrm{E}$ and $\mathrm{H}$ are "cognitively the same" for a particular problem and their cooperation will not bring any synergy, so the utility function value will be 0 . Asymmetry is represented on Fig. 3. by two curves: solid one describing the distance between actor $\mathrm{E}$ and $\mathrm{H}$ and dotted describing cognitive distance between $\mathrm{H}$ and $\mathrm{E}$.

The goal of cognitive proximity is to define and select an optimal group of actors working together from the perspective of creative problem being solved or, in other words, from the perspective of knowledge absorption and productivity, and innovation creation.

These are the two main group-related criteria that are used in the team member selection model. They are complemented by the analysis of individual criteria like education, experience, academic results, age, language skills, interpersonal capabilities, etc. Individual attributes of the existing team member have a minor influence on the model as they are already incorporated in the current performance of the team.

Next stage in the selection model deals with an analysis of potential candidates and it starts with the MBTI analysis. Then it is followed by the analysis of individual attributes of candidates including geographical location. It is not a surprise that currently many organizations consider outsourcing as a cost cutting strategy thus they are more willing to hire new employ- ee in such countries like China, India or Brazil than in Germany, Finland or US where labor costs are much more higher. For the decision making process this criterion will be combined with the competence factor in order to provide the correct answer for the choice to be made. We can assume situation that there is two candidates from which one is located close to the base team with a higher level of competency but with also with a higher costs and the second located in a different time zone with a lower level of competency but also with a much lower costs. At this point it should be decided whether it is more profitable to hire more competency for the higher long term costs but with quicker ROI as collocated team member with higher initial skills will be able to perform his daily job quite fast.

On the other hand hiring someone in the different time zone with lower level of competency might seem to be unreasonable decision however long term costs of outsourced employee are so much lower that it might be profitable to higher such person and for the initial months collocate such member within the team for the faster knowledge transfer and afterwards sending back. Crucial issue here that will determine the choice is the knowledge transfer pace for temporary collocated new team member and thus such collocation time that influence the total cost of employee.

Above five stages of analysis form a base for new team member selection model using group-related and individual characteristics of existing team members and potential candidates. The whole model is presented in Fig. 4. 


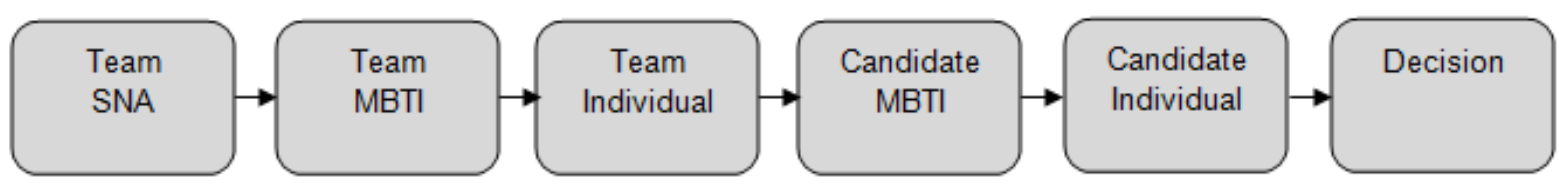

Figure 4. New team member selection mode (source: self study)

First stage of the model identifies existing team structure, communication channels and knowledge flows. It is followed by the typological analysis of team members using Myers-Briggs Type Indicator modified in order to quantify cooperation relations between different types. Last stage of the team analysis is related to the individual attributes of its members. Then potential new team members are analyzed starting with MBTI type identification and followed by individual attributes analysis including geographical location, experience and competence. In the final stage multicriteria decision is made based on the group-related and individual attributes emphasizing cooperation and social characteristics of both team members and candidates.

Such model for a new team member selection based on group-related and individual attributes can be used for example in global telecommunication companies which have plans to outsource some of their operational tasks, i.e. IT support, marketing, etc. After outsourcing these tasks will be performed jointly by internal resources and external consultants depending on the criticality of the tasks. The company that wants to outsource is sending out requests for proposals for outsourcing services and providers are proposing delivery of the services including human resources allocated for the tasks being performed. Then requesting company can use such model for the selection of optimal external candidates to be working with an internal team in order to achieve the highest possible quality of the service to be provided. In the next chapter an illustrative example of the problem and solution proposed is presented.

\section{$4 \quad$ Illustrative example}

Let us consider a team consisting of 8 members. Due to the new responsibilities acquired the team must hire one additional person. Five candidates answered for the recruitment request. The first step of the method is Team SNA. Let's define $M$ as a set of existing team members.

$$
M=\left(M_{1}, M_{2}, M_{3}, M_{4}, M_{5}, M_{6}, M_{7}, M_{8}\right)
$$

Matrix representing knowledge flow between team members is showed in Table 8.

Table 8. Knowledge flow in Team M (source: self study)

\begin{tabular}{|c|c|c|c|c|c|c|c|c|}
\hline & $\mathrm{M}_{1}$ & $\mathrm{M}_{2}$ & $\mathrm{M}_{3}$ & $\mathrm{M}_{4}$ & $\mathrm{M}_{5}$ & $\mathrm{M}_{6}$ & $\mathrm{M}_{7}$ & $\mathrm{M}_{8}$ \\
\hline $\mathrm{M}_{1}$ & $\mathrm{X}$ & 1 & 1 & 1 & 1 & 1 & 1 & 1 \\
\hline $\mathrm{M}_{2}$ & 0 & $\mathrm{X}$ & 1 & 1 & 1 & 1 & 1 & 1 \\
\hline $\mathrm{M}_{3}$ & 0 & 0 & $\mathrm{X}$ & 1 & 1 & 1 & 1 & 1 \\
\hline $\mathrm{M}_{4}$ & 0 & 0 & 1 & $\mathrm{X}$ & 1 & 1 & 1 & 1 \\
\hline $\mathrm{M}_{5}$ & 0 & 0 & 0 & 0 & $\mathrm{X}$ & 1 & 1 & 1 \\
\hline $\mathrm{M}_{6}$ & 0 & 0 & 0 & 0 & 1 & $\mathrm{X}$ & 1 & 1 \\
\hline $\mathrm{M}_{7}$ & 0 & 0 & 0 & 0 & 1 & 1 & $\mathrm{X}$ & 1 \\
\hline $\mathrm{M}_{8}$ & 0 & 0 & 0 & 0 & 0 & 1 & 1 & $\mathrm{X}$ \\
\hline
\end{tabular}

This gives following outdegree values for each of the team members:

$$
\begin{aligned}
& \operatorname{deg}^{-}\left(M_{1}\right)=7 \\
& \operatorname{deg}^{-}\left(M_{2}\right)=6 \\
& \operatorname{deg}^{-}\left(M_{3}\right)=5 \\
& \operatorname{deg}^{-}\left(M_{4}\right)=5 \\
& \operatorname{deg}^{-}\left(M_{5}\right)=3 \\
& \operatorname{deg}^{-}\left(M_{6}\right)=3 \\
& \operatorname{deg}^{-}\left(M_{7}\right)=3 \\
& \operatorname{deg}^{-}\left(M_{8}\right)=2
\end{aligned}
$$

From above it can be seen that member $\mathrm{M}_{1}$ possesses the most knowledge in the team and is a source of knowledge for all of the team members. In the opposite the member $\mathrm{M}_{8}$ is least skilled from the knowledge transfer point of view.

Next step in the method is Team MBTI. Each member of the team solves the MBTI auto-questionnaire that defines his or her psychological type. The example results of this step are following:

$$
\begin{aligned}
& \mathrm{M}_{1}=\mathrm{ISTP} \\
& \mathrm{M}_{2}=\mathrm{INTJ} \\
& \mathrm{M}_{3}=\mathrm{ESTJ} \\
& \mathrm{M}_{4}=\mathrm{ENTJ} \\
& \mathrm{M}_{5}=\mathrm{ISTJ} \\
& \mathrm{M}_{6}=\mathrm{ESTJ} \\
& \mathrm{M}_{7}=\mathrm{ISTJ} \\
& \mathrm{M}_{8}=\mathrm{INFP}
\end{aligned}
$$


Next step in the method is Team Individual where individual attributes of the team members are identified. In our example we use only two attributes such us country of residence and job role and omit others as these are enough for understanding the method. These attributes are important for the knowledge transfer point of view. Country of residence plays significant role in the cost of employee. It is not a surprise that the cost of hiring a person in Western countries is higher than in off-shored countries. Job role defines tasks and responsibilities of a team member and his or her potential in the knowledge transfer towards new team member. The hierarchy of the job roles in our example is that Ds is a most advance role requiring the most knowledge and experience called in general the competence, Dr is a medium role requiring lower but sufficient level of competence, and $\mathrm{Sp}$ is introductory role requiring basic level of competence. That also shows the possibility of knowledge transfer between team members and potential new member. Let's use the example countries F, P, S, U and example job roles Ds, Dr, Sp and identify each member by these two attributes:

$$
\begin{aligned}
& \mathrm{M}_{1}=(\mathrm{P}, \mathrm{Ds}) \\
& \mathrm{M}_{2}=(\mathrm{F}, \mathrm{Ds}) \\
& \mathrm{M}_{3}=(\mathrm{P}, \mathrm{Dr}) \\
& \mathrm{M}_{4}=(\mathrm{P}, \mathrm{Dr}) \\
& \mathrm{M}_{5}=(\mathrm{S}, \mathrm{Sp}) \\
& \mathrm{M}_{6}=(\mathrm{S}, \mathrm{Sp}) \\
& \mathrm{M}_{7}=(\mathrm{U}, \mathrm{Sp}) \\
& \mathrm{M}_{8}=(\mathrm{P}, \mathrm{Sp})
\end{aligned}
$$

Now it is time for candidate's analysis. Let's define C as a set of candidates that answered for the recruitment request for the $\mathrm{Sp}$ role.

$$
\mathrm{C}=\left(\mathrm{C}_{1}, \mathrm{C}_{2}, \mathrm{C}_{3}, \mathrm{C}_{4}\right)
$$

Their example MBTI types are:

$$
\begin{aligned}
& \mathrm{C}_{1}=\text { ENTJ } \\
& \mathrm{C}_{2}=\text { ISTJ } \\
& \mathrm{C}_{3}=\text { ESTJ } \\
& \mathrm{C}_{4}=\text { ENTJ }
\end{aligned}
$$

Last step in the method is Candidate Individual where country of residence is identified as well as required competence level. Examples countries for candidates are $\mathrm{P}, \mathrm{F}, \mathrm{C}, \mathrm{B}$ with following allocation:

$$
\begin{aligned}
& \mathrm{C}_{1}=\mathrm{F} \\
& \mathrm{C}_{2}=\mathrm{P} \\
& \mathrm{C}_{3}=\mathrm{B} \\
& \mathrm{C}_{4}=\mathrm{C}
\end{aligned}
$$

Let's define cost of hiring and keeping employee in each country and assign to it 10 points in case of the most expensive country and then a fraction of it for cheaper countries. In our example it is as follows:

$$
\begin{aligned}
& \mathrm{F}=10 \\
& \mathrm{P}=5 \\
& \mathrm{C}=2,5 \\
& \mathrm{~B}=3
\end{aligned}
$$

Then let's define the required competence level as RC and its scale from 0 to 1 where 0 means minimum required competence that the candidate can be hired and 1 as maximum required competence of candidate. The results are following:

$$
\begin{aligned}
& \mathrm{C}_{1}=0,8 \mathrm{RC} \\
& \mathrm{C}_{2}=0,5 \mathrm{RC} \\
& \mathrm{C}_{3}=0,3 \mathrm{RC} \\
& \mathrm{C}_{4}=0,3 \mathrm{RC}
\end{aligned}
$$

Now it is time in the method for comparison of all identified and defined values of candidates against existing team members. Firstly we compare MBTI types using values from Table 9 .

Table 9. Candidates vs. Team members MBTI comparison (source: self study)

\begin{tabular}{|c|c|c|c|c|c|c|c|c|}
\hline & $\mathrm{M}_{1}$ & $\mathrm{M}_{2}$ & $\mathrm{M}_{3}$ & $\mathrm{M}_{4}$ & $\mathrm{M}_{5}$ & $\mathrm{M}_{6}$ & $\mathrm{M}_{7}$ & $\mathrm{M}_{8}$ \\
\hline $\mathrm{C}_{1}$ & 0,35 & 0,4 & 0,8 & 0,6 & 0,6 & 0,8 & 0,6 & 0,35 \\
\hline $\mathrm{C}_{2}$ & 0,1 & 0,55 & 0,4 & 0,6 & 0,35 & 0,4 & 0,35 & 0,5 \\
\hline $\mathrm{C}_{3}$ & 0,15 & 0,6 & 0,6 & 0,8 & 0,4 & 0,6 & 0,4 & 0,55 \\
\hline $\mathrm{C}_{4}$ & 0,35 & 0,4 & 0,8 & 0,6 & 0,6 & 0,8 & 0,6 & 0,35 \\
\hline
\end{tabular}

Above matrix acts as a base for a decision making process regarding the best candidate. First, all columns will be multiplied by the weights according to the results from Team SNA - each column will be weighted by its outdegree value divided by the number of team members. The results are presented in Table 10 .

Table 10. Team SNA weighted matrix (source: self study)

\begin{tabular}{|c|c|c|c|c|c|c|c|c|}
\hline & $\mathrm{M}_{1}$ & $\mathrm{M}_{2}$ & $\mathrm{M}_{3}$ & $\mathrm{M}_{4}$ & $\mathrm{M}_{5}$ & $\mathrm{M}_{6}$ & $\mathrm{M}_{7}$ & $\mathrm{M}_{8}$ \\
\hline $\mathrm{C}_{1}$ & 0,31 & 0,30 & 0,5 & 0,38 & 0,23 & 0,3 & 0,23 & 0,09 \\
\hline $\mathrm{C}_{2}$ & 0,09 & 0,41 & 0,25 & 0,38 & 0,13 & 0,15 & 0,13 & 0,13 \\
\hline $\mathrm{C}_{3}$ & 0,13 & 0,45 & 0,38 & 0,5 & 0,15 & 0,23 & 0,15 & 0,14 \\
\hline $\mathrm{C}_{4}$ & 0,31 & 0,3 & 0,5 & 0,38 & 0,23 & 0,3 & 0,23 & 0,09 \\
\hline
\end{tabular}


Then each row is multiplied by the required competence factor. The results are shown in Table 11.

Table 11. Competency weighted matrix (source: self study)

\begin{tabular}{|c|c|c|c|c|c|c|c|c|}
\hline & $\mathrm{M}_{1}$ & $\mathrm{M}_{2}$ & $\mathrm{M}_{3}$ & $\mathrm{M}_{4}$ & $\mathrm{M}_{5}$ & $\mathrm{M}_{6}$ & $\mathrm{M}_{7}$ & $\mathrm{M}_{8}$ \\
\hline $\mathrm{C}_{1}$ & 0,25 & 0,24 & 0,4 & 0,3 & 0,18 & 0,24 & 0,18 & 0,07 \\
\hline $\mathrm{C}_{2}$ & 0,04 & 0,21 & 0,13 & 0,19 & 0,07 & 0,08 & 0,07 & 0,06 \\
\hline $\mathrm{C}_{3}$ & 0,04 & 0,14 & 0,11 & 0,15 & 0,05 & 0,07 & 0,05 & 0,04 \\
\hline $\mathrm{C}_{4}$ & 0,09 & 0,09 & 0,15 & 0,11 & 0,07 & 0,09 & 0,07 & 0,03 \\
\hline
\end{tabular}

Last step in our example is multiplying each row of the above matrix by the reciprocal of the Country of Residence factor and normalizing the whole matrix. The results are shown in Table 12.

Table 12. Decision matrix (source: self study)

\begin{tabular}{|c|c|c|c|c|c|c|c|c|}
\hline & $\mathrm{M}_{1}$ & $\mathrm{M}_{2}$ & $\mathrm{M}_{3}$ & $\mathrm{M}_{4}$ & $\mathrm{M}_{5}$ & $\mathrm{M}_{6}$ & $\mathrm{M}_{7}$ & $\mathrm{M}_{8}$ \\
\hline $\mathrm{C}_{1}$ & 0,41 & 0,4 & 0,67 & 0.5 & 0,3 & 0,4 & 0,3 & 0,12 \\
\hline $\mathrm{C}_{2}$ & 0,15 & 0,69 & 0,42 & 0,63 & 0,22 & 0,25 & 0,22 & 0,21 \\
\hline $\mathrm{C}_{3}$ & 0,22 & 0,75 & 0,63 & 0,83 & 0,25 & 0,38 & 0,25 & 0,23 \\
\hline $\mathrm{C}_{4}$ & 0,61 & 0,6 & 1 & 0,75 & 0,45 & 0,6 & 0,45 & 0,18 \\
\hline
\end{tabular}

Now if we summarize the values in rows we get:

$$
\begin{aligned}
& \mathrm{C}_{1}=3,09 \\
& \mathrm{C}_{2}=2,77 \\
& \mathrm{C}_{3}=3,53 \\
& \mathrm{C}_{4}=4,64
\end{aligned}
$$

That means that in our example the best candidate for the team is $\mathrm{C}_{4}$ which is the final decision point in the presented example.

\section{Further Research}

It must be stated that described example was very simple and limited only to one group related and two individual attributes. The method used simple operations as its main role was only to present the possible new method of choosing the right candidate for the existing team using jointly individual and group related attributes of both existing team members and potential new members. There are several next steps in the research that will focus on:

1) Further research and analysis of the MBTI instrument and its usage in the team building activities from the team members' personality matching perspective

2) Research and development of the team members' competence match method based on the Cognitive Proximity concept. Initial analysis of the concept suggests the usage of fuzzy sets methods in order to get optimal competence compatibilities and complementarities that generate synergy effect.

3) Development of sufficient number of individual attributes used in the general selection method.

4) Development of the general selection method based on the multicriteria decision making process.

\section{Conclusion}

The common problem of today's corporations is to acquire competent and experience staff that is capable of performing well in a fast and changing environment. Typically the recruitment process takes care of individual characteristics of potential new employees without relation to existing team that new employee will work in. This can cause a situation when well skilled new team member will not fit into existing team and instead of improving its performance will negatively affect it. As a solution for this problem a novel approach to the selection process is proposed. The solution is based on multicriteria decision model taking into consideration group-related and individual characteristics of both, existing team members and candidates. The selection model consists of five analysis stages that are concluded with sixth stage of decision point. Two main criteria for group-related attributes are Myers-Briggs Type Indicator and Cognitive Proximity concept.

\section{$7 \quad$ References}

[1] Adamiecki K. - Harmonization as one of the main foundations of scientific management [in] About Scientific Management. Państwowe Wydawnictwo Ekonomiczne 1970 (in Polish).

[2] Adams S.G. - An Investigation of the Attributes Contributing to Team Effectiveness of Engineering and Science Faculty [at] $29^{\text {th }}$ ASEE/IEEE Frontiers in Education Conference, San Juan, Puerto Rico, November 10-13, 1999.

[3] Armstrong M. - Human Resources Management. Strategy and Action. Wydawnictwo Profesjonalnej Szkoły Biznesu, Kraków 1996 (in Polnish). 
[4] Boschma R.A. - Proximity and Innovation. A Critical Assessment [in] Regional Studies, No. 39(1), 2005, pp. 61-74.

[5] Cakrt M. - Typology of personality for managers. Wydawnictwo Helion, Gliwice 2006 (in Polish).

[6] Carlyn M. - An Assessment of the Myers-Briggs Type Indicator [in] Journal of Personality Assessment, 41(5), 1977.

[7] Chen S.J. - An Integrated Methodological Framework for Project Task Coordination and Team Organization in Concurrent Engineering [in] CONCURRENT ENGINEERING: Research and Applications, Vol. 13, No. 3, September 2005.

[8] Chen S.J., Lin L. - Modeling Team Member Characteristics for the Formation of a Multifunctional Team in Concurrent Engineering [in] IEEE Transactions on Engineering Management, Vol. 51, No. 2, May 2004

[9] Chen M.M., Luckett P.F., Schulz A.K-D. - The Effects of Cognitive Style and Diversity on Decision-Making Dyads: An Empirical Analysis in the Context of a Complex Task [in] Behavioral Research in Accounting, Vol. 15, 2003.

[10] Gorla N., Lam Y.W. - Who Should Work with Whom? Building Effective Software Project Teams [in] Communications of the ACM, Vol. 47, No. 64 June 2004.

[11] Grabowska G., Wojnar J. - Social capital and proximity in ICT companies [in] Theoretical and practical aspects of urban and regional development (ed. T. Markowski, M. Turała). Warsaw 2009, pp. 244264.

[12] Hayes N. - Managing Teams: A Strategy for Success. South-Western CENGAGE Learning 2002.

[13] Hoegl M. - Smaller teams - better teamwork: How to keep project teams small. Business Horizons, No. 48, 2005, pp. 209-214.

[14] Jackson K., Taylor I. - The Power of Difference. Exploring the value and brilliance of diversity in teams. Management Books 2000 Ltd., 2008.
[15] Jamka B. - Human Resources Management Search and Development of Employees. Oficyna Wydawnicza Szkoły Głównej Handlowej, Warszawa 1997 (in Polish).

[16] Katzenbach J.R., Smith D.K. - The Discipline of Teams [in] Harvard Business Review, JulyAugust 2005.

[17] Levi D., Slem C. - Team work in research and development organizations: The characteristics of successful team [in] International Journal of Industrial Ergonomics, No. 16, 1995, pp. 29-42.

[18] Ludwiczyński A. - Strategic Human Resources Management. Polska Fundacja Promocji Kadr - Zarząd, Warszawa 2000 (in Polish).

[19] Opt S.K., Loffredo D.A. - Communicator Image and Myers-Briggs Type Indicator Extroversion Introversion [in] The Journal of Psychology, No. 137(6), 2003, pp. 560-568.

[20] Pirola-Merlo A., Mann L. -The relationship between individual creativity and team creativity: aggregating across people and time [in] Journal of Organizational Behavior, No. 25, 2004, pp. 235257.

[21] Saaty T.L. - How to make a decision: The Analytic Hierarchy Process [in] European Journal of Operational Research, No. 48, 1990, pp. 9-26.

[22] Stapelton J.L. - Effects of Team Composition on Problem Solving: An Empirical Investigation of the Assembly Effect [in] The Delta Pi Epsilon Journal Spring, Vol. 49, Issue 2, 2008, pp. 94-108.

[23] Walukiewicz S. - Four Forms of Capital and Proximity. Working paper. Systems Research Institute of the Polish Academy of Sciences, WP-3-2007.

[24] Wojnar J. - MBTI as a measure of Emotive Proximity [in] Analiza Systemowa w Finansach i Zarządzaniu (ed. J. Hołubiec), Warszawa 2010 (in Polish). 